\title{
Study of the thermodynamic efficiency of solid fuel preparation systems of a thermal power plant based on an exergy analysis of the operation of subsystems
}

\author{
Saule Kamarova ${ }^{1}$, Saule Abildinova ${ }^{1}$, and Angel Terziev ${ }^{2 *}$ \\ ${ }^{1}$ Department of Industrial Heat Technology, Almaty University of Power Engineering and \\ Telecommunications, Almaty, Kazakhstan \\ ${ }^{2}$ Department of Power Engineering and Power Machines, Technical University of Sofia, 8 Kliment \\ Ohridski blvd., 1000 Sofia, Bulgaria
}

\begin{abstract}
Own energy consumption needs at combined heat and power plant depends on the type and installed capacity of the main and auxiliary equipment installed on-site, as well as the type of the fuel and combustion method used. The coal dust preparation system, in turn, is the most energyintensive part of coal mining. Therefore, methods for improving the operation of the fuel path of a combined heat and power plant and the technology for producing coal dust are very relevant. The present study proposes a comprehensive methodology for determining the thermodynamic efficiency of solid fuel preparation systems at combined heat and power plant 2 (CHP-2) in the city of Temirtau of the Republic of Kazakhstan. Outdated equipment is operated at the CHP and there is virtually no automation of technological processes related with the solid fuel preparation system. The scientific novelty of the work is the theoretical study and analysis of the thermodynamic efficiency of an individual dust preparation system with an intermediate hopper when grinding coal. The thermal and thermodynamic calculations based on the determination of exergy efficiency for individual units of the dust system and the system as a whole allow to propose means to increase the efficiency of the coal industry and give recommendations to reduce energy costs for the plant's own needs. As a recommendation to reduce energy costs for the preparation of coal dust, the installation of a crushing press with a studded surface is proposed, which allows grinding large pieces of coal to optimal sizes $(25 \mathrm{~mm})$ in the absence of preliminary crushing of the material on-site. An automation scheme for the entire dust preparation system is proposed, including automation of the operation of the intermediate coal dust bin. Automatic control of the supply of coal dust from the intermediate hopper allows to determine the exact fuel consumption of the steam boiler, which were not permissible under the previous conditions of the dust system due to the use of a semi-mechanical method of regulating the supply of coal dust to the boiler.
\end{abstract}

\footnotetext{
*Corresponding author: aterziev@tu-sofia.bg
} 


\section{Problem description}

Energy saving in combined heat and power plant sector is inextricably linked with energy and fuel savings and leads to increased requirements in terms of quality of calculation, design and exploitation of the power plants.

The aim of this study is to propose a comprehensive methodology for determining the thermodynamic efficiency of solid fuel preparation systems at combined heat and power plant and develop recommendations for obtaining rational parameters of the fuel preparation system.

The object of study is the CHP-2 of Temirtau, Karaganda region of the Republic of Kazakhstan. The facility was commissioned in 1973 and it is functioning as a source of energy for the enterprises and the city. Steam boilers of TP-81 (E-420-140) combined heat and power plants are equipped with two closed dust preparation systems with an intermediate hopper and with a ball drum mill (BDM) for each boiler. In total, 6 TP-81 boilers with a total capacity of $2520 \mathrm{t} / \mathrm{h}$ running on Karaganda coal (industrial product) with a water content of $\mathrm{W}=11.0 \%$ were installed at CHP-2. The humidity of the final dust $\mathrm{W}^{\mathrm{s}}=1.2 \%$. Based on boiler tests performed in 2003, the maximum humidity of the incoming fuel was $14 \%$ [3]. The working humidity of the fuel at the preliminary stage of drying can be reduced to $\mathrm{W}_{\mathrm{p}}=9.0 \%$.

Figure 1 shows an individual closed circuit system for the preparation of coal dust with an intermediate hopper with drying of coal with hot air and recirculation of the drying agent after separation in a cyclone for the reuse of transport of highly concentrated dust into the burners of the TP- 81 boiler.

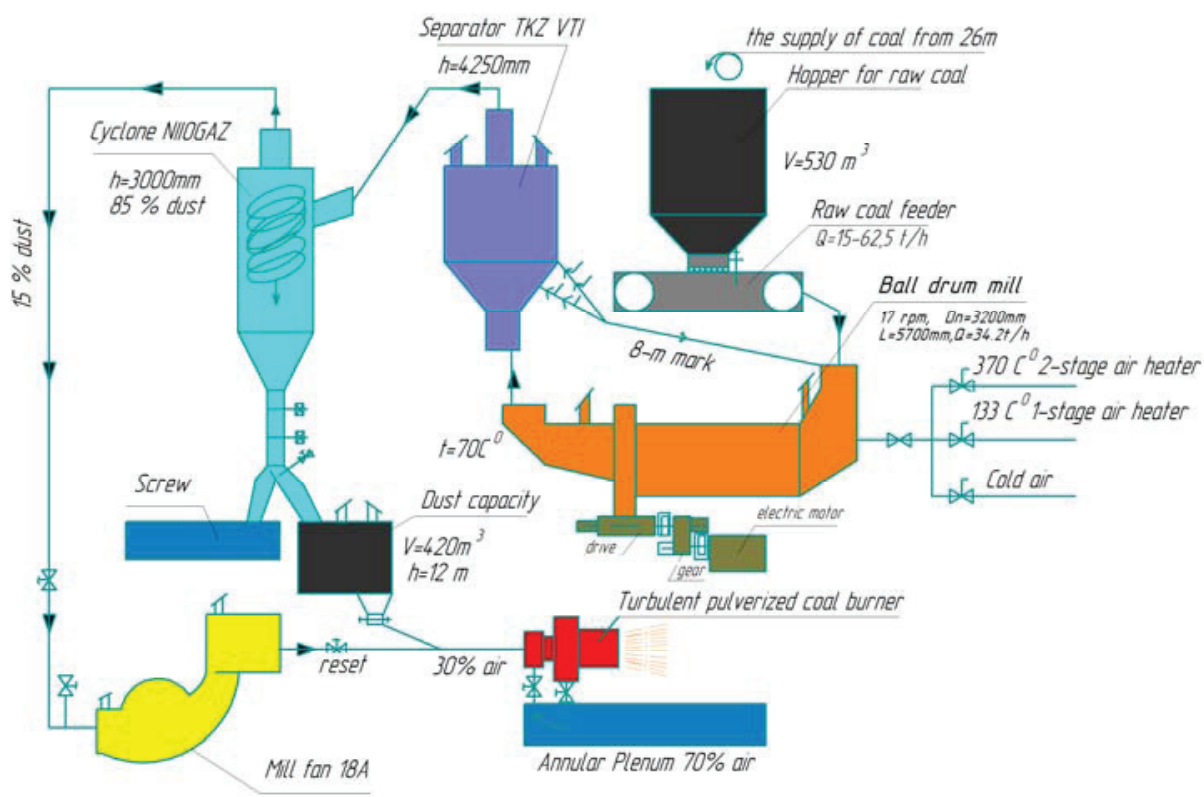

Fig. 1. Schematic diagram of an individual closed dust preparation system with a ball-drum mill and an intermediate hopper at CHP-2 of ArcelorMittal Temirtau JSC (AMT JSC)

The schematic diagram of the preparation of coal dust at CHP-2 of AMT JSC, presented in Figure 1, differs from the traditionally accepted individual dust preparation schemes with an intermediate bunker for ballast. The distinctive features of the solid fuel preparation system installed at CHP-2 include the following: 
- there is a periodic warming up and thawing of coal coming to the station, in terms of the proximity of the distance to the coal mining field;

- thawing of fuel is carried out only in exceptional cases with hot air heated in a steam running heater, when there is severe freezing of fuel at very low air temperatures during the winter;

- the rest of the time, coal is dried with hot air from the air heaters of steam boilers only before fuel is supplied to the ballast;

- the temperature of the drying agent is regulated by mixing hot air after the second stage of the air heater at a temperature of $370{ }^{\circ} \mathrm{C}$, slightly superheated air after the first stage of the air heater and cold atmospheric air;

- early crushing coal stages are not monitored resulting in coals with large pieces (more than $25 \mathrm{~mm}$ ) which further are fed into the mill;

- because coal enters continuously into the crude fuel bunkers of the boiler room, equipped with gratings of $40 \times 40 \mathrm{~mm}$ in size, and installed above the bunker, the mill experiences overload in operation;

- the absence of a stage of crushing fuel leads to significant increases in energy consumption for grinding, a decrease in grinding and drying performance of the mill;

- due to the lack of material opportunities to replace old equipment with new equipment at the CHP, semi-mechanical regulation of the main operations and the dust preparation system is still being applied.

Taking into account the noted shortcomings in the operation of the fuel path and in the scheme for preparing coal dust at CHP-2, the following measures can be proposed to improve the quality of the fuel supply path and the dust preparation system:

1. Installation of a crushing press having a studded surface. When the press acts on the surface of the grate with the remnants of pieces of coal stuck on the surface of the super-bunker grating, large pieces of coal are crushed to sizes less than $25 \mathrm{~mm}$. The proposed hydraulic press has a low specific energy consumption, is convenient during operation and allows to reduce the consumption of electric energy directly for grinding the fuel at the ball drum mill.

2. Automation of the entire dust preparation system, including automation of the operation of the intermediate coal dust bin, will make it possible to control the processes of fuel milling, the operation of the equipment and the parameters of the processed coal dust. The proposed automation scheme for ball drum mill:

- Reduces the specific consumption of electric energy;

- maintains the stability of the fractional composition of coal dust;

- improve the maximum possible productivity of the mill, depending on the characteristics of coal and a dust system at various levels of mill loading from 80 up to $95 \%$ of the maximum possible load;

- optimizes the fuel grinding process;

- ensure the continuous monitoring of the filling level of the intermediate dust bin, the fuel consumption of the boiler unit depends on the volume of coal dust;

- the presence of automatic technological regulators will allow maintaining the parameters of the dust and gas mixture behind the grinding installation and making technical decisions in various emergency situations.

Performing an exergy analysis will allow to assess the efficiency of the existing solid fuel preparation system at ArcelorMittal Temirtau CHP-2 JSC and determine ways to increase fuel economy and reduce electric energy for the plant's own needs. The exergy method is based on a comprehensive methodology for calculating the thermodynamic efficiency of a fuel preparation system, including theoretical relations for determining the exergy effect of individual structural units and fuel preparation systems as a whole [4]. 
Thermodynamic analysis of systems, as well as establishing the relationship between thermodynamic efficiency and technical and economic indicators, allows to determine the external and internal energy losses in the system, divided by system sections and justify the cost structure of thermal and electric energy received at a combined heat and power plant [5].

To perform an exergy analysis of the coal dust preparation system, the balance technological scheme shown in Figure 2 was adopted. Based on this technological scheme, the thermal and exergy balance of the dust system was prepared in order to determine its performance criteria.

The exergy balance of the solid fuel preparation system - the process of grinding and further refinement steps are compiled with the main blocks - subsystems (Figure 2):

- Block I, where completely crude fuel is dried in the open air at the CHP and is naturally crushed during transportation on a conveyor belt and loading fuel into a hopper with a grate due to impact of pieces of fuel on the surface of the walls of the hopper and grate;

- Block II, where the drying of crude fuel with hot air from the steam air heater is carried out and further grinding in the ballast;

- Block III, where high concentration dust is supplied with a mill fan to the steam boiler burners.

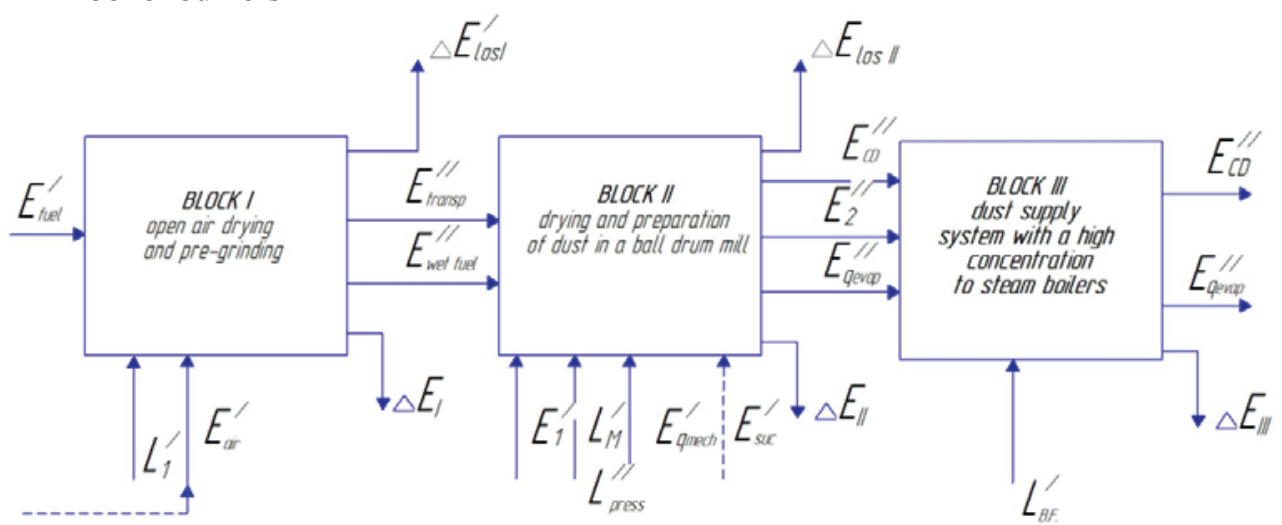

Fig. 2. Thermal balance of a closed fuel preparation system with combined drying and dust preparation processes

Notations of energy flows used in the thermal balance of the fuel preparation system in Figure 2 are as follow:

- $\quad E_{\text {Fuel }}^{\prime}$ - exergy of fuel for preliminary crushing stages without a crusher to sizes less than $40 \times 40 \mathrm{~mm}$;

- $\quad E_{\text {Trans }}^{\prime \prime}$ - exergy of the fuel, dried in the open air, transported by a belt conveyor to the raw fuel bunker;

- $E_{\text {Air }}^{\prime}$ - exergy of atmospheric air blown through stacks of coal;

- $\quad E_{\text {Wetfuel }}^{\prime \prime}$ - exergy of moisture of the initial fuel;

- $\quad E^{\prime}$ - exergy of the drying agent (hot air);

- $\quad E_{\text {qmech }}^{\prime}$ - exergy of the heat flow released during the work of grinding parts of a ball mill;

- $\quad E_{\text {Suck }}^{\prime}$ - exergy of sucked air;

- $\quad L_{M}, L_{M}^{\prime}, L_{p r}^{\prime \prime}, L_{b f}^{\prime}$ - energy costs for the drive of the conveyor belt, for the drive of the mill, for the drive of the hydraulic press and the blower fan; 
- $\Delta E_{\text {Lost }}^{\prime}$ - loss of exergy in the block $\mathrm{P}-1$;

- $\Delta E_{1}, \Delta E_{2}, \Delta E_{3}$ - internal exergy loss in blocks P1-P3;

- $\Delta E_{\text {LostII }}$ - loss of exergy during grinding of fuel in block II;

- $\quad E_{C O}^{\prime \prime}$ - exergy of finished coal dust;

- $\quad E_{2}^{\prime \prime}$ - exergy of the spent drying agent without taking into account the enthalpy of evaporated moisture;

- $\quad E_{\text {qevap }}^{\prime \prime}$ - the exergy of the heat flux spent on the evaporation of moisture in the fuel.

$$
\sum \mathrm{E}_{M}^{\prime}+\sum \mathrm{E}_{q}^{\prime}+\sum L^{\prime}=\sum \mathrm{E}_{M}^{\prime \prime}+\sum \mathrm{E}_{q}^{\prime \prime}+\sum L^{\prime \prime}+\Delta \mathrm{E}+\Delta \mathrm{E}_{\text {Loss }}
$$

where:

- $\quad \mathrm{E}_{M}^{\prime}, \mathrm{E}_{M}^{\prime \prime}$ - exergy of material flows at the entrance to the fuel preparation system and at the exit, respectively;

- $\mathrm{E}_{q}^{\prime}, \mathrm{E}_{q}^{\prime \prime}$ - exergy of heat fluxes entering the system and resulting from the operation of the system itself;

- $\quad L^{\prime}, L^{\prime \prime}$ - electric energy at the inlet and outlet of the fuel preparation system;

- $\Delta \mathrm{E}, \Delta \mathrm{E}_{\text {Loss }}$ - internal and external loss of exergy in the fuel preparation system.

The total exergy efficiency of the fuel preparation system can be expressed with the following equation:

$$
\eta=\frac{E_{f p}^{\prime \prime}+\sum_{k=1}^{S} E_{a f}^{\prime \prime}}{\sum_{i=1}^{n} E_{i}^{\prime}+\sum_{j=1}^{m} L_{j}}
$$

where: $E_{f p}^{\prime \prime}$ - exergy of the prepared fuel, which is actually a coal dust, sent for combustion in the boiler burners; $E_{a f}^{\prime \prime}$ - exergy of associated flows.

For a closed fuel preparation system with combined drying and dust preparation processes (Figure 2), the exergy efficiency of individual subsystems and the entire system as are determined with the expression (3).

The exergy efficiency of individual units and the fuel preparation system itself determine the overall performance of the system. The exergy efficiency of block I, which is responsible for preliminary drying and grinding is expressed with:

$$
\eta_{I}=\frac{E_{\text {Trans }}^{\prime \prime}}{\sum_{i=1}^{n} E_{d i}^{\prime}+\sum_{j=1}^{m} L_{d j}^{\prime}}
$$

where: exergy of heated and dried fuel is considered as useful components of the exergy balance.

The exergy efficiency of block II, which is responsible for the final drying and dust preparation is as follow: 


$$
\eta_{I I}=\frac{E_{F u e l}^{\prime}+E_{q e v a p}^{\prime \prime}+E_{d}^{\prime \prime}}{\sum_{i=1}^{n} E_{d i}^{\prime}+\sum_{j=1}^{m} L_{d j}^{\prime}}
$$

where exergy of heated and dried fuel is considered as useful components of the exergy balance.

\section{Experimental study. Results}

The exergy efficiency analysis makes it possible to evaluate the efficiency of the solid fuel preparation system and the contribution of the individual stages of its conversion and make an adequate conclusion about energy costs when changing the characteristics of the fuel [4]. To calculate the exergy efficiency of the fuel preparation system and its subsystems, the main indicators of fuel and coolants in the fuel supply and dust preparation system are used, as shown in Table 1.

Table 1. Summarized data about the fuel used

\begin{tabular}{|l|c|}
\hline Brand and type of fuel & $\begin{array}{c}\text { Industrial product } \\
\text { (stone coal) }\end{array}$ \\
\hline Material water content, $\mathrm{W}^{\mathrm{r}}, \%$. & 27.6 \\
\hline A-ash content, $\mathrm{A}^{\mathrm{r}}, \%$ : & 28 \\
\hline Volatile yield, $\mathrm{V}^{\mathrm{g}}, \%$ : & 0.7 \\
\hline Sulfur content, $\mathrm{S}^{\mathrm{r}}, \% ;$ & 20222 \\
\hline Lower calorific value of fuel, $Q_{l}^{f}, \mathrm{~kJ} / \mathrm{kg}$ & 18.2 \\
\hline Fineness grinding factor, $R_{90}, \%$ & 50.6 \\
\hline Quantity of fuel used per hour, $q, \mathrm{t} / \mathrm{h}$ & 338 \\
\hline Air temperature at the outlet of the air heater, $t_{\text {gair }},{ }^{\circ}:$ & -7 \\
\hline Ambient air temperature $t_{\text {exair }},{ }^{\circ} \mathrm{C}:$ & 30 \\
\hline Boiler room temperature $t_{\text {broom }},{ }^{\circ} \mathrm{C}:$ & 6.9 \\
\hline Air consumption at the outlet of the air heater, $G_{\text {air }}, \mathrm{m}^{3} / \mathrm{s}$ & Drum type, $320 / 570$ \\
\hline Mill type & \\
\hline
\end{tabular}

The calculation results for an individual dust preparation system with an intermediate hopper with hot air drying of Karaganda coal (industrial product) are presented in the form of an exergy Sankey diagram in Figure 3 and Table 2.

Exergies of material flows, i.e. coal, a drying agent, prepared coal dust, included in Eqs (3) up to (6) are defined in various ways:

- the exergy of the fuel after the crushing stage of $E_{F u e l}^{\prime}$ is determined by ND Zakharov [5], taking into account the well-known characteristics of coal as the lowest chemical exergy $E_{\text {lchem }}^{\prime}$ :

$$
E_{\text {lchem }}=\left[1.009+\frac{0.13 O^{p}+0.11 W^{p}}{100-\left(A^{p}+W^{p}\right)}\right] Q_{l}^{p}
$$


where $O^{p}$ is the oxygen content in the working fuel; $A^{p}, W^{p}, Q_{l}^{p}$ are humidity, ash and lower heat of combustion of the working fuel.

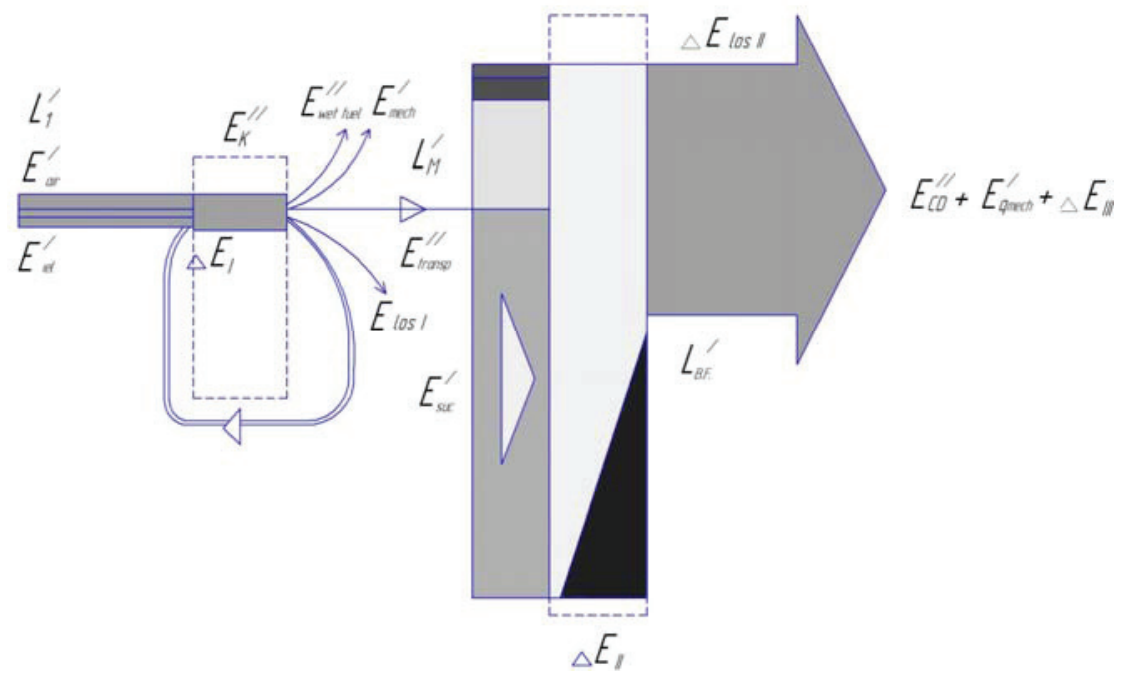

Fig. 3. Diagram of exergy flows for an individual dust preparation system with an intermediate coal dust bin

Table 2. Calculation results of the exergy analysis of the fuel supply and dust preparation systems with a maximum fuel moisture content $\mathrm{W}^{\mathrm{r}}=14.0 \%$.

\begin{tabular}{|c|l|c|c|c|c|}
\hline & Name of item/system & $\begin{array}{c}\text { Exergy of } \\
\text { flow at the } \\
\text { inlet of } \\
\text { each item, } \\
\mathrm{kJ} / \mathrm{kg}, E^{\prime}\end{array}$ & $\begin{array}{c}\text { Exergy of flow } \\
\text { at the oulet of } \\
\text { each item, } \\
\mathrm{kJ} / \mathrm{kg}, E^{\prime \prime}\end{array}$ & $\begin{array}{c}\text { Losses, } \\
\mathrm{kJ} / \mathrm{kg}, \\
E_{\text {losses }}\end{array}$ & $\begin{array}{c}\text { Exergy } \\
\text { efficiency, \% }\end{array}$ \\
\hline 1 & Pre-drying and grinding & 12.69 & 0.58 & 3.78 & 6.6 \\
\hline 2 & $\begin{array}{l}\text { Drying and Dust } \\
\text { Preparation at BDM }\end{array}$ & 554.7 & 50.21 & 314.47 & 20.9 \\
\hline 3 & $\begin{array}{l}\text { High concentration dust } \\
\text { supply system }\end{array}$ & 312.85 & 87.21 & - & 27.9 \\
\hline 4 & $\begin{array}{l}\text { For the entire system } \\
\text { with high concentration } \\
\text { dust }\end{array}$ & 1099.65 & 183.63 & 318.25 & 23.5 \\
\hline
\end{tabular}

The exergy of a homogeneous substance (hot and cold air) is determined with the following relation:

$$
\Delta_{0} e=\int_{T_{0}}^{T_{j}} c_{p} d T+q_{j}+\int_{T_{0}}^{T_{j}} c_{p} d T-T_{0}\left(\int_{T_{0}}^{T_{j}} c_{p} \frac{d T}{T}+\frac{q_{j}}{T_{j}}+\int_{T_{j}}^{T} c_{p} \frac{d T}{T}\right)+\frac{R}{M} T_{o} \ln \frac{p}{p_{o}},
$$

where $T_{o}$ and $p_{o}$ are the temperature and pressure of the surrounding media, expressed in $\mathrm{K}$ and $\mathrm{Pa} ; \mathrm{T}$ and $\mathrm{p}$ are current values of the temperature and pressure; $q_{j}, T_{j}$ are heat and temperature of the phase change in $\mathrm{kJ} / \mathrm{kg}$ and $\mathrm{K} ; c_{p}$ - specific heat capacity, $\mathrm{kJ} /(\mathrm{kg} . \mathrm{K})$; $R$ - Universal gas constant, $\mathrm{kJ} /(\mathrm{kmol} . \mathrm{K}) ; M$ - molecular weight if the substances. 
The exergy of the heat flux is calculated by the formula $[6,7,8]$ :

$$
\mathrm{E}_{\mathrm{q}}=\tau_{\mathrm{c}} \cdot \mathrm{Q}_{l}^{\mathrm{p}}=\left(1-\frac{\mathrm{T}_{\mathrm{o}}}{\mathrm{T}}\right)
$$

Steam exergy is determined by Eq. 8 (per $1 \mathrm{~kg}$ of fuel) $[2,6]$ :

$$
\begin{gathered}
\mathrm{E}_{\mathrm{q}}=\tau_{\mathrm{c}} \cdot \mathrm{Q}_{l}^{\mathrm{p}}=\left(1-\frac{\mathrm{T}_{\mathrm{o}}}{\mathrm{T}}\right) \\
\mathrm{E}_{\text {steam }}^{\prime}=q_{s t}\left(h_{s c}-h_{s i}-T_{0}\left(s_{s c}-s_{s i}\right)\right)
\end{gathered}
$$

where $h_{s i}(\mathrm{~kJ} / \mathrm{kg})$ and $s_{s i}(\mathrm{~kJ} /(\mathrm{kgK}))$ are enthalpy and entropy of steam at $\mathrm{T}_{\mathrm{o}}$ and $\mathrm{p}_{\mathrm{o}}$; $h_{s c}(\mathrm{~kJ} / \mathrm{kg})$ and $s_{s c}(\mathrm{~kJ} /(\mathrm{kgK}))$ are enthalpy and entropy of steam at $\mathrm{T}$ and $\mathrm{p} ; q_{s t}$ specific steam consumption per $1 \mathrm{~kg}$ of fuel, $\mathrm{kg} / \mathrm{kg}$.

The calculated data indicated in table 1 show that block I, of preliminary periodic drying and grinding, has a low exergy coefficient (6.6\%), as well as block II, of continuous drying and dust preparation on a ball mill (20.9\%). In terms of energy efficiency preliminary drying and grinding amounted to $6.6 \%$, where the exergy loss of $3.78 \mathrm{~kJ} / \mathrm{kg}$ is associated with the conditions of drying the fuel with a steam heater, where significant losses due to moisture and freezing of the fuel are presence. When organizing continuous pre-drying of the fuel, the exergy efficiency of block I will increase as the working humidity of the fuel decreases from $14 \%$ to $9 \%$ and this leads to a decrease in the exergy of the working fuel after the crushing stage $\mathrm{E}_{F u e l}^{\prime}$, determined by formula (6). The exergy losses $\Delta \mathrm{E}_{I}$ decrease from $3.78 \mathrm{~kJ} / \mathrm{kg}$ up to $2.05 \mathrm{~kJ} / \mathrm{kg}$, which resulting in increased exergy efficiency of block I from $6.6 \%$ up to $9.8 \%$.

Exergy losses in the drying and dust preparation unit (Figure 4) are due to high consumption of electric energy for grinding $-314.47 \mathrm{~kJ} / \mathrm{kg}$ of fuel. The annual power production of CHPP-2 is 2890878 thousand $\mathrm{kWh}$, electricity consumption for own needs is 370000 thousand $\mathrm{kWh}$. In general, electricity consumption for dust preparation in terms of the total electricity consumption for auxiliary needs of CHPP-2 is $17.16 \%$, and electricity consumption for crushing coal from the total electricity generation is $2.2 \%$. During the grinding process, large pieces of fuel with sizes exceeding $25 \mathrm{~mm}$ get into the mill, since the preliminary stage of coarse and fine crushing of fuel is not carried out at the power plant under consideration and pieces of coal with a size of $40 \times 40 \mathrm{~mm}$ fall into the raw fuel hopper. To reduce exergy losses and to reduce the size of crushing, a device for crushing coal is proposed, containing a hydraulic hammer, a ramming plate, a hydraulic cylinder. A positive result is achieved by reducing the idling time of technological equipment for the preparation and supply of fuel to boilers, the time to start supplying coal by combining the work of crushing and fractionation with a predetermined sieve composition, ensuring efficient operation of the fuel supply and optimal loading of the mill.

The fuel preparation system at CHP-2 is very outdated, the main equipment of the fuel path is 2 up to 2.5 operational lives of such facilities, so many fuel supply and fuel treating processes are carried out by semi-mechanical drive devices. In this regard, here is proposed a scheme for automating the operation of an intermediate coal dust bin.

The scheme (Figure 5) for measuring the dust level using vibration level tool allows accurately determination of the amount of coal dust supplied to the burner devices, evaluate the grinding performance [10] of the mill and refine the technical and economic performance of the steam boiler [9]. 


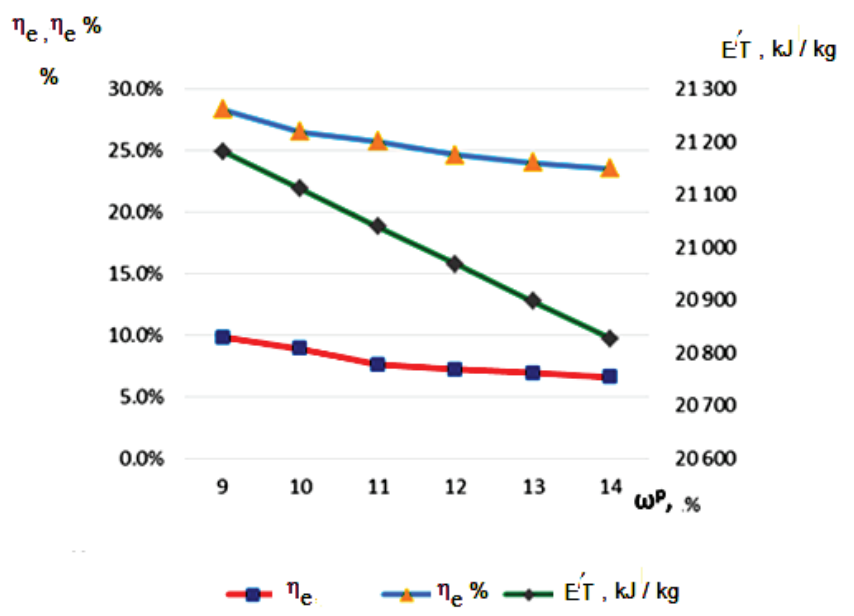

Fig. 4. Relation of the exergy efficiency of a high-concentration coal-dust preparation system, in terms of preliminary drying and grinding unit for fuel, and fuel exergy of moisture $\mathrm{W}^{\mathrm{r}}$

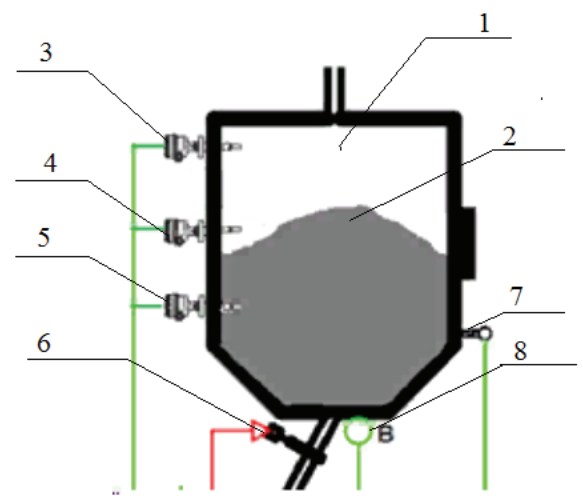

Fig. 5. Measuring the level of coal dust with a vibration level tool: 1 - coal dust bin, 2- coal dust, 3, 4, 5 - vibration level meter (measuring the upper limit, middle, lower limit), 6-valve gate, 7thermometer for measuring dust temperature, 8 -scale.

Continual monitoring of the level of coal dust in the dust bin, as well as discrete monitoring is not difficult, but various factors influence the choice, such as dimensions, measurement conditions [12].

Tracking the exact amount will provide full control of the dust level in the hopper, since it is necessary to constantly monitor not only the upper, but also the lower dust level in the hopper [12].

As a result of the proposed measures to improve the operation of the fuel preparation and dust preparation system of CHP-2, an increase in the total exergy efficiency was obtained from $23.5 \%$ up to $=28.3 \%$.

\section{Conclusion}

A complex methodology is proposed for calculating the thermodynamic efficiency of solid fuel preparation systems (intermediate product of coal of the Karaganda basin) based on the exergy method, which includes theoretical dependences for determining the exergy efficiency of individual structural units and for entire fuel preparation system. Measures 
aimed at improving the energy efficiency of the fuel preparation and dust preparation systems of the power plant are proposed.

As a result of the introduction of additional stages in the fuel processing process, an increase in the exergy efficiency of the fuel supply and dust preparation systems was obtained. The improvement in the system resulting in increased energy efficiency amounting from $23.5 \%$ up to $=28.3 \%$.

The fineness of grinding of different coals is selected based on technical and economic considerations. A decrease in the size of a grain of dust leads to an increase in the specific surface area of the fuel, which favors its combustion, but this is associated with an increase in energy consumption for dust preparation. With coarseness of grinding, the energy consumption for dust preparation decreases, however, the loss of heat from mechanical underburning increases. In this regard, it is necessary to optimize the dust preparation system to reduce energy costs and improve the quality of coal grinding.

\section{References}

1. G. R. Mingaleeva, Y. N. Zatsarinnaya, E. K. Vachagina, Analysys of performace of system fuel supply and dust preparation working with solid fuels, Journal of Problems in Energetics, (2005), 1.

2. P. V. Roslyakov, M. A. Izumov, Environmental friendly technologies used in coals processing in CHP, Book, (2003).

3. A. Turblek, Current state and problems in the operation of power equipment, Journal of Energetics, (2013).

4. G. R. Mingaleeva, Y. N. Zatsarinnaya, Y. G. Nazmeev, Calculation sequence and thermodynamic efficiency of an individual coal preparation system with an intermediate hopper, Newsletters of Journal Energetics, (2006), 2.

5. Y. G. Nazmeev, G. R. Mingaleeva, Analysis of thermal and thermodynamic efficiency of dust preparation systems, Newsletters of Journal Energetics, (2006), 6.

6. Y. G. Nazmeev, I. A. Konahina, Organization of energy technology complexes in the petrochemical industry, Book, (2001).

7. T. Srinivas, A. Gupta, B. V. Reddy and P. K. Nag, Parametric analysis of coal based combined cycle power plant, Int. J. Energy, (2006), 30.

8. V. Ramaprabhu, R. P. Roy, A Computational Model of a Combined Cycle Power Generation Unit, J. of Energy Resources Technology, (2004), 126.

9. H. H. Erdem, Comparative energetic and exergetic performance analyses for coal-fired thermal power plants in Turkey, International Journal of Thermal Sciences, 48, Issue 11, (2009).

10. S. N. Kamarova, S. N. Abildinoiva, S. K. Rasmuhametova, Analysis of the operation of the fuel preparation system at TPP-2 in Temirtau, International Conference "I ${ }^{\text {st }}$ anniversary readings of F. K. Boyko", 1, Pavlodar, (2020).

11. L. N. Sidelkovsky, V. N. Yurenev, Boiler plants at industrial enterprises, Book, (1988).

12. P. M. Luzin, V. E. Maslov, Selection of optimal systems for preparing fuel for combustion, (1981).

13. V. A. Demntev, The work of JSC Central Research Institute for the Development of Intelligent Functions of Process Control Systems for Energy Facilities, Book "Theory and practice of building and functioning of industrial control system at thermal power plants", (2000). 